\title{
Author Correction: Hexokinase-2 depletion inhibits glycolysis and induces oxidative phosphorylation in hepatocellular carcinoma and sensitizes to metformin
}

\author{
Dannielle DeWaal', Veronique Nogueira1, Alexander R. Terry (10 1, Krushna C. Patra ${ }^{1,5}$, Sang-Min Jeon (1) 1,6, \\ Grace Guzman (10 ${ }^{3}$, Jennifer $\mathrm{Au}^{4}$, Christopher P. Long ${ }^{4}$, Maciek R. Antoniewicz ${ }^{4} \&$ Nissim Hay H,2 $^{1,2}$
}

Correction to: Nature Communications https://doi.org/10.1038/s41467-017-02733-4, published online 31 January 2018.

In the originally published version of this Article, the colours of the bars in Fig. $4 \mathrm{~b}$ were inadvertently switched during the production process, such that 'HK2-Dox' and 'HK2+Dox' were depicted in red and 'Nt-Dox' and 'Nt+Dox' were depicted in blue. These errors have now been corrected in both the PDF and HTML versions of the Article.

Published online: 26 June 2018

\begin{abstract}
(c) (1) Open Access This article is licensed under a Creative Commons Attribution 4.0 International License, which permits use, sharing, adaptation, distribution and reproduction in any medium or format, as long as you give appropriate credit to the original author(s) and the source, provide a link to the Creative Commons license, and indicate if changes were made. The images or other third party material in this article are included in the article's Creative Commons license, unless indicated otherwise in a credit line to the material. If material is not included in the article's Creative Commons license and your intended use is not permitted by statutory regulation or exceeds the permitted use, you will need to obtain permission directly from the copyright holder. To view a copy of this license, visit http://creativecommons.org/licenses/by/4.0/.
\end{abstract}

(๑) The Author(s) 2018

\footnotetext{
${ }^{1}$ Department of Biochemistry and Molecular Genetics, College of Medicine, University of Illinois at Chicago, Chicago, IL 60607, USA. ${ }^{2}$ Research \& Development Section, Jesse Brown VA Medical Center, Chicago, IL 60612, USA. ${ }^{3}$ Department of Pathology, College of Medicine, Cancer Center, University of Illinois Hospital and Health Science Chicago, Chicago, IL 60612, USA. ${ }^{4}$ Department of Chemical and Biomolecular Engineering, Metabolic Engineering and Systems Biology Laboratory, University of Delaware, Newark, DE 19716, USA. ${ }^{5}$ Present address: Massachusetts General Hospital Cancer Center, Harvard Medical School, Boston, MA 02114, USA. 'Present address: College of Pharmacy, Ajou University, Yeongtong-gu, Suwon-siGyeonggi-do 443-749, Korea Correspondence and requests for materials should be addressed to M.R.A. (email: mranton@udel.edu) or to N.H. (email: nhay@uic.edu)
} 